\title{
Research On Countermeasures for the Standardization of Mental Health Education in Colleges and Universities in the New Period
}

\author{
Chunming $\mathrm{Xu}^{1}$ Can Wang ${ }^{2 *}$ Nan Yang ${ }^{3}$ \\ ${ }^{1}$ Student Development and Services Office, Dalian University of Science and Technology, Dalian, Liaoning 116052, \\ China \\ ${ }^{2}$ School of Digital Technology, Dalian University of Science and Technology, Dalian, Liaoning 116052, China \\ ${ }^{3}$ School of Economics and Management, Dalian University of Science and Technology, Dalian, Liaoning 116052, China \\ *Corresponding author. Email: 652196979@qq.com
}

\begin{abstract}
The standardization of mental health education in institutions of higher learning is an important guarantee to improve their mental health service ability and level. In the new period, the work of mental health education in colleges and universities is changing with the requirements of the society. Therefore, on the basis of strengthening policy interpretation, colleges and universities should pay attention to the professional development of psychological counselors, establish a standardized psychological crisis prevention and intervention system, and actively construct interactive experiential mental health education classes to further promote psychological education.
\end{abstract}

Keywords: Higher education, mental health, standardization, professional

\section{INTRODUCTION}

Since the reform and opening up 40 years ago, mental health education in colleges and universities in China has developed rapidly, and the ways and methods of mental health education and counseling service have been constantly improved[1]. However, the mental health education in colleges and universities is still in the primary stage of development due to the great differences among colleges and universities in the degree of attention, investment in funds, working facilities, etc., which leads to the unbalanced and irregular development of mental health education. Therefore, it is necessary to study how to build a standardized mental health education service system.

\section{MULTIDIMENSIONAL INTERPRETATION OF THE STANDARDIZED CONSTRUCTION OF COLLEGE STUDENTS' MENTAL HEALTH EDUCATION IN THE NEW PEROID}

\subsection{Standardization Construction In The New Period Should Focus On The Improvement Of Soft Power Of Mental Health Education}

In the new period, the state and local governments have issued policy documents to support the mental health education career, each college mental health education center is in big construction, development, hardware facilities generally promote, construction have an appointment room, consulting room, music room, sand table room relaxation, catharsis, steering room, meeting room, etc., significantly enhance center environment, but on the use of mental health center function, also cannot achieve the ideal effect, many function of the hardware configuration of idle condition. Mental health education in colleges and universities should not only focus on hardware construction, but also highlight the development of soft power. For example, enhance the effectiveness of thematic education activities, carry out colorful and distinctive mental health education activities, and mobilize 
the enthusiasm and initiative of students to participate in mental health education activities[2]. Improve the "soft power" of the teaching staff, pay attention to the professional development, emotional belonging and psychological development level of the mental health education team, and enhance the enthusiasm of all university teachers to participate in the mental health education work.

\subsection{The Standardization of the New Period Should Pay Attention to the Expertise-based Psychological Consultation}

In 2017, the Ministry of Labor canceled the exam for psychological counseling, making counseling no longer a licensed job. The Chinese psychological society clinical and counseling psychology in professional organizations and professional personnel registered system standard for psychological counselors is defined: "refers to the system studied professional knowledge of clinical or counseling psychology, system of psychological therapy and practical professional skills training and supervision, is engaged in the work of the psychological counseling and psychotherapy professionals." This requires psychological consultants to have a professional background, solid basic knowledge, systematic supervision of practical experience and personal experience, only in this way can better provide professional help for visitors[3]. In order to help visitors benefit from the professional consultation relationship, we should carry out standardized psychological consultation service on campus, establish professional consultation relationship, strictly set up consultation and strictly observe professional ethics. Therefore, the school should pay attention to the training of psychological counselors, help them get professional growth, and constantly build expert psychological counseling service team.

\subsection{Standardization Construction in The New Period Should Prevent the Impact of Bad Network Information}

The popularization and application of mobile network in the new era increases the risk of young college students being impacted by bad network information. Some Internet violence information intrudes into the campus, especially some bad information including violence, suicide, murder and pornography, which seriously threatens the physical and mental health development of college students. Some students can not resist the temptation of the Internet, the ability to distinguish right from wrong is poor, deep in campus online loans, online gambling, online fraud, games and other bad campus behavior, causing them to bear serious psychological pressure and a huge mental burden. College psychological health education work, therefore, should stick to a good network of mental health education, regulating the Internet use, create the healthy, active, and pure cyberspace, standardize the use of network early warning information platform, set up students with the bad network information of the firewall, prevent adverse psychological impact of the network information for young college students.

\section{COLLEGES AND UNIVERSITIES SHOULD PAY ATTENTION TO THE PROFESSIONAL DEVELOPMENT OF PSYCHOLOGICAL COUNSELORS}

\subsection{Strictly Observe Professional Ethics}

The professional ethics of psychological counselors is the professional standard that psychological counselors should follow to ensure that every visitor seeking professional help receives professional services and benefits from them so as to avoid harm. The professional ethics of psychological counselors is an important guarantee for schools to standardize the work of psychological counseling. It is also the "laws and regulations" of counseling. Following professional ethics can not only ensure that students benefit from counseling, but also protect each psychological counselor himself[4]. Colleges and universities should ensure that every psychological counselor receives professional ethics training of no less than 16 credit hours every two years to constantly enhance ethical awareness. In addition, colleges and universities should set up ethical guidance groups to discuss ethical issues.

\subsection{Focus On Technology and Training}

The problems presented by the visitors in the consultation are multi-faceted and complex. In order to effectively solve their problems, psychological counselors are required to have a professional height and look at the problems from multiple perspectives. Psychological counselor is a profession that needs continuous training and systematic professional training is the key to ensure the professional growth and development of psychological counselor. Therefore, colleges and universities should formulate training plans every year, in combination with the actual needs of full-time and part-time staff, to ensure that psychological counselors of different professional orientations receive systematic continuing education and training, with the annual standard of no less than 60 class hours, continuously strengthen the training of mental 
health education teachers, and build a psychological work team with excellent quality and skills.

\subsection{Case Supervision and Personal Experience}

Case supervision means that experienced counseling experts examine the process of psychological counseling to help the supervised understand the process of psychological counseling, so that the supervised can benefit from counseling. Individual psychological case supervision and group supervision can promote the personal growth of psychological counselors, and have great help to professional development. Therefore, psychological counseling is not done behind closed doors. A person's ability is often very limited, so it is necessary to establish their own counseling framework through supervision, so as to better help visitors. Colleges and universities should ensure that each psychological counselor receives no less than 30 hours of individual or group supervision every year. Psychological counseling is a complex work for psychological professionals. Before becoming a psychological counselor, one must improve his/her personality strength and self-awareness[5]. Therefore, the school should pay attention to personal experience when recruiting psychological professionals, and encourage psychological counselors to accept personal experience after joining.

\section{ESTABLISH A STANDARDIZED PSYCHOLOGICAL CRISIS PREVENTION AND INTERVENTION SYSTEM IN UNIVERSITIES}

The early detection, timely intervention and effective control of students' psychological crisis are the basis for maintaining the safety and stability of schools and the important guarantee for students' mental health and life safety. Psychological crisis prevention and intervention is not only a systematic project, but also a work with a high degree of standardization, which needs the guarantee of the system and the coordination and cooperation of all departments of the school. The establishment of scientific psychological crisis early warning and intervention system can effectively prevent the occurrence of psychological crisis events and prevent the spread of crisis and trauma. At present, most schools have set up "24-hour life assistance hotline", which can solve the problems encountered by students in the first time. However, according to the relevant requirements of the Mental Health Law, there are always irregularities in psychological crisis intervention. Therefore, there is still a big gap between the quality of service and the management process of professional institutions.

First of all, due to the lack of professionals, the process of psychological counseling will always occur irregularities. Secondly, the ability of collaborative education is insufficient. Many colleges do not have psychiatrists or employ part-time off-campus psychiatrists, which often leads to the inability or inability to make accurate assessments of students' conditions in a timely manner, thus delaying the onset of illness. Thirdly, the network psychological crisis early warning ability is insufficient, some schools only pay attention to students' normal performance, but ignore the monitoring of the network information that students browse. Finally, the early warning and intervention of psychological crisis is a systematic and dynamic process, which requires the cooperation of all departments of the school to track and monitor the students dynamically. However, there is no resultant force in the actual work, and the dynamic psychological changes of students cannot be presented. Taking the characteristics of mental health work in colleges and universities as an example, the construction of psychological crisis prevention and intervention system should be started from the following aspects.

First, construct "early-warning human information database". Colleges and universities should establish a long-term mechanism of psychological survey and review, carry out psychological survey and review on college students, screen out the early-warning population, establish a database of early-warning students, and regularly track and help the early-warning students. At the beginning of each semester, colleges and universities for students to search, that the implementation of the family, family conflicts, economic difficulties, emotional setbacks, academic warning track and support work, such as special group of serious psychological disorder, mental disease, and suicidal students to establish specialized psychological archives, implement a regular tracking and dynamic management.

Second, establish students' dynamic psychological files. Colleges and universities should combine the census data, monthly and weekly information, psychological counseling files and so on to establish students' psychological growth files for the four years of college, which is conducive to help schools to master the information of "key persons"[6].

Third, institutional guarantee. Colleges and universities should formulate the information communication system of psychological crisis, the report of high-risk groups and the rapid referral of students with psychological diseases, so as to standardize the process of crisis intervention and enhance the scientific nature and effectiveness of prevention intervention. A post-recovery evaluation, interview and follow-up mechanism shall be established to evaluate the students who return to school after suspension due to psychological problems and obtain a written certificate from a specialized hospital with psychiatric diagnosis qualification. During the treatment of students, the school establishes good communication with their guardians to form a joint effort of family and school, so as to help students get out of the psychological dilemma as soon as possible, prevent relapse of illness, and effectively protect students' mental health and life safety.

Fourth, psychological crisis early warning and intervention outstanding effectiveness. Colleges and universities should carry out targeted and targeted help plans for "key 
students" through regular screening of information database data, so as to achieve precise measures; Set up a 24-hour life service hotline, and the center takes turns to answer students' calls for help; Go into the college regularly, have a consultation with the instructor and the psychological station master, and have an in-depth discussion on some complex and difficult cases.

Fifth, the establishment of network psychological crisis early warning system. The establishment of the network crisis early warning information platform is an important measure for the early warning of the psychological crisis of young college students in the new era. It monitors the sensitive information and vocabulary that students browse on the Internet all the time and gives timely warning once found.

\section{ACTIVELY CONSTRUCT INTERACTIVE AND EXPERIENTIAL MENTAL HEALTH EDUCATION CLASSES}

The compulsory course of college students' mental health education is an important way to popularize the knowledge of mental health. In order to give full play to the role of the main channel of classroom teaching and promote the organic unity of knowledge, psychological experience and behavior training, Zhoukou Normal University issued the document "some opinions on strengthening the mental health education of college students" in 2016, which proposed the training objectives, curriculum structure, teacher structure, curriculum evaluation, guaranteed the validity of the compulsory courses of mental health education and science for college studentscurriculum supervision regulations.

First of all, the traditional "college students' mental health education" is mainly taught, and students' participation and enthusiasm are generally not high. Teachers should include interaction and experience, construct interactive experiential classes, adopt group activities, case teaching, meditation experience, behavioral training and other forms, improve the attraction and appeal of the courses, help college students understand the basic knowledge of mental health, and pay attention to students' feelings in the classroom.

Secondly, constantly improve the curriculum structure. Many colleges and universities have organized and compiled school-based textbooks for College Students' Mental Health Education, and according to their own school-running characteristics, reformulated curriculum training objectives, and divided the curriculum into knowledge classes and activity classes. Knowledge class teaches theory in the form of psychological cases to help college students understand the basic knowledge of mental health. Activity class pays attention to students' feelings and experience. This way of combining theory with practice is a classroom teaching form worthy of reference. Thirdly, optimize the teaching staff structure. Colleges and universities should absorb teachers and counselors of psychology, pedagogy and ideological and political education and let them join the teaching team. Teachers with different professional backgrounds have rich work cases and experience of students. They can infiltrate mental health knowledge from different fields, make classroom teaching more interesting and promote the diversity of teachers of mental health education courses. Before the beginning of each semester, we will carry out collective observation and discussion activities of the course, and effectively help the teachers to master the method of conducting interactive experiential classes through observation, discussion, lecture, trial lecture, class attendance and class evaluation.

\section{CONCLUSION}

Instead of serving only as an inspection course, colleges can require that each class have a classroom recorder to record each student's performance and participation in the class and use it as an important basis for a student's final grade. In addition, teachers can implement the student mutual evaluation mechanism, in which each student can grade the other members of his/her own group, so as to enhance the mutual understanding among students and improve the participation and interaction of classroom teaching. At the same time, the curriculum of mental health education should have a complete teaching and evaluation system to enrich the supervision and evaluation of the curriculum. For example, the teaching content and teaching effect can be effectively supervised and evaluated by random sampling inspection, or the teaching quality can be investigated by sending questionnaires among students. Through the above methods, colleges and universities should take multiple measures to gradually develop the course construction of college students' mental health education towards the direction of refinement, specialization and diversification.

\section{REFERENCES}

[1] Fang Hongzhi, Pan Siyu, The development and Trend of Mental Health Education for College Students in China in the past 40 years of reform and opening up, Contemporary Education science, 2019, pp.51-63.

[2] Chinese Psychological Society, Registration standards for professional clinical and counseling psychology institutions and professional personnel registration system of Chinese Psychological Association, Journal of Psychology, 2018, pp.1303-1313.

[3] Chinese Psychological Society, Code of Ethics for Clinical and Counseling Psychology of Chinese Psychological Society, Journal of Psychology, 2018, pp. 1314-1322. 
[4] Holloway E L,Overseeing the overseer:Contextualizing training insupervision, J Counsel Dev,1994, pp.526-530.

[5] Meng Fu, Zhang Jie, Chen Xiangyi, et al, "Untouchable Girl" Family Therapy orientation group Supervisor, Chinese Journal of Mental Health, 2014, pp. 926-931.

[6] Yao Benxian, Mental health education in schools, Hefei: Anhui University Press, 2008, pp. 193. 